\title{
Asistan hekimlerin Obstrüktif Uyku Apne Sendromu ile ilgili bilgi ve tutumlarının değerlendirilmesi
}

\author{
The Evaluation of knowledge and attitudes of resident doctors about Obstructive Sleep \\ Apnea Syndrome
}

\author{
Selma Tekin, Nilüfer Emre
}

Gönderilme tarihi:23.03.2021

Kabul tarihi:04.05.2021

\section{Öz}

Amaç: Obstrüktif uyku apne sendromu (OUAS), uyku bozukluklarının önemli bir kısmını oluşturur. OUAS tanısı çoğu zaman gözden kaçabilmektedir. OUAS, sistemik birçok hastalığa sebep olması nedeniyle uzman tıp doktorluğunda farklı bölümlerin karşısına çıkmaktadır. Çalışmada farklı bölümlerdeki asistan hekimlerin OUAS ile ilgili bilgi ve tutumlarını değerlendirmek amaçlandı.

Gereç ve yöntem: Çalışma tanımlayıcı kesitsel tipte olup Pamukkale Üniversitesi Hastanesi'nde görev yapan 88 asistan hekimi (Aile hekimi, dahiliye, nöroloji, göğüs hastalıkları ve kulak burun boğaz) kapsamaktadır. Çalışmaya katılan asistan hekimlere internet üzerinden demografik bilgilerin de dahil edildiği, Türkçeye çevrilmiş obstruktif uyku apne bilgi tutum (OSAKA) anketi gönderilmiştir. OSAKA anketi, 18 bilgi değerlendirme sorusu ve 5 tutum değerlendirme sorusundan oluşan 23 soruluk bir ankettir.

Bulgular: Çalışmaya katılan 68 asistan hekimin OSAKA bilgi puanı ile yaş, cinsiyet, uzmanlık alanı, asistanlık yılı arasında istatistiksel olarak anlamlı bir fark bulunmadı $(p>0,05)$. Ancak sayısal olarak göğüs hastalıkları ve kulak burun boğaz bölümlerinin bilgi puanları diğer bölümlerden fazlaydı. Tutum puanlarıyla yaş, asistanlık yılı arasındaki ilişki incelendiğinde yaşla tutum puanları arasında anlamlı bir ilişki bulunmazken, asistanlık yılı ile ortalama tutum puanları arasında anlamlı pozitif yönde korelasyon saptandı $(r=0,257 ; p=0,035)$.

Sonuç: Asistan hekimlik eğitim sürecinde OUAS bilgi ve tutumunun bölümler arasında belirgin farklılık göstermediği ancak bazı eksikliklerin olduğu saptandı. Bunun giderilmesi amacıyla hem tıp fakültesinde hem de asistanlık eğitim süresince çeşitli eğitim faaliyetleri ve uyku tıbbı rotasyonlarının düzenlenmesi gerekmektedir.

Anahtar kelimeler: Obstrüktif uyku apne sendromu, OSAKA, bilgi, tutum, asistan hekim.

Tekin S, Emre N. Asistan hekimlerin Obstrüktif Uyku Apne Sendromu ile ilgili bilgi ve tutumlarının değerlendirilmesi. Pam Tıp Derg 2021;14:676-683.

\begin{abstract}
Purpose: Obstructive sleep apnea syndrome (OSAS) constitutes an important part of sleep disorders. OSAS diagnosis can often be overlooked. Because OSAS causes many systemic diseases, these patients come across different departments in specialist medical practice. In our study, we aimed to evaluate the knowledge and attitudes of assistant physicians in different departments about OSAS.

Materials and methods: The study is a descriptive cross-sectional type and includes 88 residet doctors (family physicians, internal medicine, neurology, pulmonology diseases and otolaryngology) working at Pamukkale University Hospital. The obstructive sleep apnea knowledge and attitude (OSAKA) questionnaire, which includes demographic information on the internet, was sent to the resident doctors participating in the study. The OSAKA questionnaire is a 23-question survey consisting of 18 knowledge questions and 5 attitude questions.

Results: There was no statistically significant difference between the OSAKA knowledge score and age, gender, specialty area, and year of residency among 68 resident doctor participating in the study $(p>0.05)$. However, numerically, the knowledge scores of pulmonology and otolaryngology departments were higher than other departments. When the relationship between attitude scores and age, resident year was examined, no significant correlation was found between age and attitude scores, while a significant positive correlation was found between the resident year and the mean attitude scores.

Conclusion: We found that OSAS knowledge and attitude did not differ significantly between departments in the residency training process, but there were some deficiencies. In order to remedy this, it is necessary to organize various educational activities and sleep medicine rotations both in the medical school and during the assistantship education.
\end{abstract}

Key words: Obstructive sleep apnea syndrome, OSAKA, knowledge, attitude, resident doctor.

Tekin S, Emre N. The Evaluation of knowledge and attitudes of resident doctors about Obstructive Sleep Apnea Syndrome. Pam Med J 2021;14:676-683.

Selma Tekin, Dr. Öğr. Üye. Pamukkale Üniversitesi Tıp Fakültesi, Nöroloji Anabilim Dalı, Denizli, Türkiye, e-posta: selmabilgintekin@gmail. com (https://orcid.org/0000-0003-1999-0510) (Sorumlu Yazar)

Nilüfer Emre, Dr. Öğr. Üye. Pamukkale Üniversitesi Tıp Fakültesi, Aile Hekimliği Anabilim Dalı, Denizli, Türkiye, e-posta: nilemre83@gmail. com (https://orcid.org/0000-0002-6519-0920) 


\section{Giriş}

Uyku bozuklukları, kişide kısa ve uzun dönemde ciddi problemlere yol açan bununla ilişkili olarak da son yıllarda önemi oldukça farkedilen bir sorundur. Obstrüktif uyku apne sendromu (OUAS), uyku bozukluklarının oldukça sık bir sebebi olup, uykuda solunum bozukluklarının en yaygın görülen tipidir [1]. Dünya Sağlık Örgütü tarafından dünya çapında yaklaşık 100 milyon kişinin OUAS'ı deneyimlediği belirtilmiştir. OUAS, uyku sırasında üst hava yollarının tekrarlayan kısmi veya tam olarak tıkanması olup bu da uyku bölünmesi, hipoksi ve uyanıklıklara yol açması ile karakterizedir [2].

OUAS tanısı, saatte toplam 5 apne ve hipopne varlığıyla konur ve buna gündüz uykululuğu, uykuda iç çekmeler, uyku bölünmeleri, gündüz yorgunluğu ve konsantrasyon bozuklukları eşlik eder [3]. OUAS ciddi hastalık yüküne yol açar ve küresel sağlık sorunları olan hipertansiyon, inme, diyabetes mellitus, depresyon gibi kardiyovasküler, metabolik ve psikiyatrik bozukluklar için bağımsız bir risk faktörü olup, trafik kazalarının da önemli bir sebebidir [4]. Bir meta-analizde OUAS prevalansı \%9-38 arasında değişmekte olup, bu durumun yaşla birlikte artış gösterdiği, erkek cinsiyet ve obezlerde daha sık görüldüğü belirtilmiştir. Türkiye'de de yapılan bir çalışmada OUAS prevalansı \%0,9-1,9 arasında bulunmuştur [5].

Uyku tıbbı, tıp fakültesi müfredatında yeterince yer almamaktadır. Almohaya ve ark.'nın [6] yapmış olduğu bir çalışmada tıp fakültesinde uyku tıbbı eğitiminin ortalama 2,6 $\pm 2,6$ saat olduğu ve yapılan Tıp Eğitiminde Uyku Bilgisinin Değerlendirilmesi (ASKME) anketinde \%60'dan az performans sergilendiği ortaya konmuştur. Bu bilgi yetersizliği, uyku bozuklukları olan hastaları tanıda gecikme ve tedavide yetersizliklerle sağlık hizmetine daha büyük bir maliyete neden olmaktadır.

Türkiye'de de uyku tıbbı hekim sayısının az olması nedeniyle, uyku bozukluğu olan hastalar başta aile hekimleri olmak üzere, nörolog, psikiyatrist, göğüs hastalıkları, kulak-burunboğaz ve diğer dahili birimlere başvurmaktadırlar [7].

Bu çalışmada, tıpta uzmanlık eğitiminin önemli bir aşaması olan asistanlık eğitiminde, obstrüktif uyku apne sendromunun farkındalığının, asistan hekimlerin bilgi ve tutumlarının değerlendirilmesi amaçlandı.

\section{Gereç ve yöntem}

Araştırma Şubat-Mart 2021 tarihleri arasında tanımlayıcı-kesitsel olarak tasarlandı. Çalışmanın evreni, Pamukkale Üniversitesi Tıp Fakültesi Hastanesi'nde görev yapan $(n=88)$ aile hekimliği asistanları, dahiliye asistanları, nöroloji asistanları, göğüs hastalıkları asistanları ve kulak burun boğaz (KBB) asistanlarından oluşmaktadır. Örneklem seçilmeyerek evrenin tümüne ulaşılması hedeflendi. Araştırmadaki verileri elde etmek için literatür taraması sonucu oluşturulan demografik özellikler (yaş, cinsiyet, uzmanlık alanı, asistanlık yılı, meslek yılı, kronik hastalık varlığı, ailede OUAS tanılı hasta olma, OUAS ile ilgili eğitim alma, OUAS ile ilgili bir toplantı konferans vb bir etkinliğe katılma, OUAS'dan şüphelendiği hastası olma) ile birlikte OUAS bilgi ve tutumunu değerlendirmek için Schotland ve Jeffe [8] geliştirdiği obstruktif uyku apne bilgi tutum (OSAKA) anketi Türkçe'ye çevrildi ve kullanıldı. OSAKA anketi, 18 bilgi değerlendirme sorusu ve 5 tutum değerlendirme sorusundan oluşan 23 soruluk bir ankettir. OSAKA anketinde OUAS ile ilgili bilgi ölçen 18 soru doğru-yanlış ve bilmiyorum seçeneklerinden oluşur. Doğru seçenekler 1 puan olarak, bilmiyorum seçeneği yanlış cevap olarak kabul edilerek 0 puan olarak belirlendi. $\mathrm{Bu}$ nedenle, alınabilecek toplam puan 0 ile 18 arasında değişmektedir. Ayrıca 5 ifadeden oluşan tutum değerlendirme sorularının, ilk ikisi OUAS'ın klinik bir durum olarak önemini değerlendirir. Yanıtları 1'den (önemli değil) 5'e (son derece önemli) kadar değişen 5'li Likert şeklindedir. Kalan üç tutum sorusu, kişinin OUAS hastalarını teşhis etme ve tedavi etme konusundaki güvenine odaklanır ve yanıtları 1'den (kesinlikle katılmıyorum) 5'e (kesinlikle katılıyorum) kadar değişen 5'li Likert şeklindedir. 2 maddelik önem ve 3 maddelik güven alt ölçeklerinin her biri ve 5 maddelik genel tutum ölçeği için ortalama tutum puanları hesaplanmıştır. Anket formu asistan hekimlere internet üzerinden gönderildi ve çalışmaya katılmak isteyen hekimler internet üzerinden anket formunu doldurdu.

$\mathrm{Bu}$ çalışma, Pamukkale Üniversitesi Girişimsel Olmayan Klinik Araştırmalar Etik Kurulu'nun onayı ile Helsinki bildirgesine uygun olarak yapıldı. 


\section{İstatistiksel analiz}

İstatistiksel analiz sonuçları, ortalama \pm standart sapma ve sayı ve yüzde olarak verildi. Verilerin normal dağılıma uygunluğu değerlendirilerek normal dağılım gösterenlerde İki Ortalama Arasındaki Farkın Önemlilik Testi ve Varyans Analizi; normal dağılım göstermeyenlerde Mann-Whitney $U$ testi ve Kruskal Wallis Varyans Analizi kullanılarak karşılaştırmalar yapıldı. Ayrıca sürekli değişkenlerin arasındaki ilişkiler Spearman korelasyon analiziyle incelendi. İstatistiksel analizler IBM SPSS 21.0 (Statistical Package For Social Sciences) paket programı kullanılarak yapıldı. İstatistiksel anlamlılık düzeyi $p<0,05$ olarak alındı.

\section{Bulgular}

Çalışmaya $68(\% 77,2)$ asistan hekim katıldı. Asistan hekimlerin yaş ortalamaları 28,28 $\pm 2,04$ ve \%60,3'ü ( $n=41)$ kadındı. Asistan hekimlerin $\% 57,4$ 'ü (n=39) OUAS ile ilgili bir eğitim aldığını ve \%8,8'i de $(n=6)$ OUAS ile ilgili bir toplantı, kongre veya çalışmaya katıldığını belirtti. Tablo 1 'de asistan hekimlerin demografik özellikleri yer almaktadır.

Asistan hekimlerin OSAKA bilgi puanı ile demografik veriler karşılaştırıldığında, yaş, cinsiyet, uzmanlık alanı, asistanlık yılı, ailede OUAS tanılı hasta olma ve eğitim alma durumuna göre bilgi puanlarında istatistiksel olarak anlamlı bir fark bulunmadı $(p>0,05)$. Tablo 2 'te asistan hekimlerin demografik özellikleri ile OSAKA anketi bilgi puanları gösterilmektedir. Tüm katılımcıların ortalama OSAKA bilgi puanı \pm SD 12,78 $\pm 1,96$ (7-17) idi. Aile hekimliği asistanlarının bilgi puanı ortalaması 12,64 $\pm 2,37$,

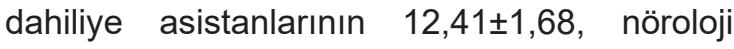
asistanlarının 13,00 $\pm 1,15$, KBB asistanlarının $13,20 \pm 1,92$, göğüs hastalıkları asistanlarının $14,17 \pm 1,16$ 'dır.

OSAKA anketinde yer alan sorulara doğru yanıt oranları Tablo 3'te gösterilmiştir. Ankette yer alan hiçbir soru katılımcıların tümü tarafından doğru yanıtlanmamıştır. Asistan hekimler tarafından bilinme oranı en yüksek sorular \%98,5 (n=67) ile birinci sırada,13. soru (Tedavi edilmeyen obstrüktif uyku apnesi yüksek trafik kazası insidansıyla ilişkili olması), \%97,1 (n=66) ile ikinci sırada 6. sorudur (Obstrüktif uyku apne tanısında gece boyu uyku çalışması altın standart olmasıdır.). Ancak asistan hekimlerin bilme oranı en düşük olan sorular \%20,6 (n=14) ile 8. soru (Lazer destekli uvuloplastinin, ağır obstrüktif uyku apnesi için uygun bir tedavi olma durumu) ve \%33,8 $(n=23)$ ile 7 . sorudur (CPAP (sürekli pozitif hava basıncı) tedavisi burun tıkanıklığına sebep olmasıdır).

Tutum sorularının ikisi OUAS'ın öneminin farkındalığı ile ilişkiliyken, 3'ü de OUAS'ı tanımlama ve yönetmede kendine güven ile ilişkiliydi. Katılımcıların önem tutumu, güven tutumu ve ortalama tutum puanları sırasıyla $4,36 \pm 0,74, \quad 3,02 \pm 0,70$ ve $3,56 \pm 0,49$ olarak bulundu. Katılımcıların \%82,4'ü $(n=56)$ OUAS'ın "çok önemli" veya "son derece önemli" bir klinik bozukluk olduğunu ve \%80,9'u ( $n=55)$ OUAS için risk altındaki hastaları tanımlamanın "çok önemli" veya "son derece önemli" olduğunu belirtti. Ancak yalnızca \%23,5'i (n=16) OUAS olan hastaları yönetme konusunda kendinden emin hissettiğini ve yalnızca \%17,6'sı $(n=12)$ da CPAP tedavisi olan hastaları yönetme konusunda kendine güvendiğini belirtti. OUAS hastalarını yönetmede kendine güvenme KBB asistanlarında istatistiksel olarak anlamlı derecede yüksekti $(p=0,023)$. CPAP tedavisialan hastaları yönetmede kendine güvenme, nöroloji ve aile hekimliği asistanlarında istatistiksel olarak anlamlı derecede düşüktü $(p=0,003)$. Tablo 4'de asistan hekimlerin OSAKA anketinin tutum kısmına ilişkin cevapları yer almaktadır.

OSAKA anketinde bilgi puanı ile ortalama tutum puanı, önem ve güven tutum puanları karşılaştırıldığında; bilgi ile ortalama tutum puanı ve önem tutum puanları arasında ilişki bulunmazken, bilgi ve güven tutum puanları arasında pozitif yönde zayıf düzeyde ilişki saptandı $(r=0,239 ; p=0,05)$. Tutum puanlarıyla asistanlık yılı arasındaki ilişki incelendiğinde, ortalama tutum puanlarıyla asistanlık yılı arasında pozitif yönde korelasyon saptandı. $(r=0,257, p=0,035)$. Ancak yaş ile tutum puanları arasında herhangi bir ilişki saptanmadı (Tablo 5). 
Tablo 1. Asistan hekimlerin demografik özellikleri

\begin{tabular}{|c|c|c|}
\hline Demografik özellikler & $\mathrm{n}$ & $\%$ \\
\hline \multicolumn{3}{|l|}{ Cinsiyet } \\
\hline Kadın & 41 & 60,3 \\
\hline Erkek & 27 & 39,7 \\
\hline \multicolumn{3}{|l|}{ Uzmanlık alanı } \\
\hline Aile hekimliği & 28 & 41,2 \\
\hline Dahiliye & 22 & 32,4 \\
\hline Nöroloji & 7 & 10,3 \\
\hline KBB & 5 & 7,4 \\
\hline Göğüs & 6 & 8,8 \\
\hline \multicolumn{3}{|l|}{ Asistanlık yılı } \\
\hline 1. yıl & 11 & 16,2 \\
\hline $1-3$ yıl & 46 & 67,6 \\
\hline$>3$ yıl & 11 & 16,2 \\
\hline \multicolumn{3}{|l|}{ Kronik hastalık } \\
\hline Evet & 6 & 8,8 \\
\hline Hayır & 62 & 91,2 \\
\hline \multicolumn{3}{|c|}{ Ailede OUAS hasta tanısı olma } \\
\hline Evet & 6 & 8,8 \\
\hline Hayır & 62 & 91,2 \\
\hline \multicolumn{3}{|c|}{ OUAS hakkında eğitimi alma } \\
\hline Evet & 39 & 57,4 \\
\hline Hayır & 29 & 42,6 \\
\hline \multicolumn{3}{|c|}{ OUAS ile ilgili herhangi bir toplantı, konferans } \\
\hline \multicolumn{3}{|l|}{ vb. katılma } \\
\hline Evet & 6 & 8,8 \\
\hline Hayır & 62 & 91,2 \\
\hline \multicolumn{3}{|c|}{ OUAS'tan şüphelendiği hastası olma } \\
\hline Evet & 54 & 79,4 \\
\hline Hayır & 14 & 20,6 \\
\hline
\end{tabular}

OUAS: Obstrüktif uyku apne sendromu

Tablo 2. Asistan hekimlerin demografik özellik ile OSAKA anketi bilgi puanı arasındaki ilişki

\begin{tabular}{|c|c|c|}
\hline Demografik özellikler & Mean $\pm S D$ & $p$ \\
\hline Cinsiyet $^{\mathrm{a}}$ & & $Z:-0,332 p=0,740$ \\
\hline Kadın & $12,76 \pm 2,16$ & \\
\hline Erkek & $12,81 \pm 1,64$ & \\
\hline Uzmanlık alanı ${ }^{\mathrm{b}}$ & & $\mathrm{F}: 1,064 p=0,382$ \\
\hline Aile hekimliği & $12,64 \pm 2,37$ & \\
\hline Dahiliye & $12,41 \pm 1,68$ & \\
\hline Nöroloji & $13,00 \pm 1,15$ & \\
\hline KBB & $13,20 \pm 1,92$ & \\
\hline Gögüs & $14,17 \pm 1,16$ & \\
\hline Asistanlık yılıb & & $\mathrm{F}: 0,029 p=0,971$ \\
\hline 1. yıl & $12,91 \pm 1,37$ & \\
\hline $1-3$ yıl & $12,76 \pm 2,15$ & \\
\hline$>3$ & $12,73 \pm 1,73$ & \\
\hline Ailede OSAS hasta tanısı ${ }^{a}$ & & $Z:-0,077 p=0,938$ \\
\hline Evet & $12,83 \pm 1,32$ & \\
\hline Hayır & $12,77 \pm 2,02$ & \\
\hline OSAS eğitim almac & & $\mathrm{T}: 0,488 p=0,121$ \\
\hline Evet & $12,92 \pm 3,12$ & \\
\hline Hayır & $12,59 \pm 2,21$ & \\
\hline
\end{tabular}


Tablo 3. Asistan Hekimlerin OSAKA anketindeki bilgi sorularına verilen doğru cevapların oranı

\begin{tabular}{|c|c|c|c|c|c|c|c|}
\hline & $\begin{array}{l}\text { Total } \\
\mathrm{n}=68 \%\end{array}$ & $\begin{array}{l}\mathrm{AH} \\
\mathrm{n}=28 \%\end{array}$ & $\begin{array}{l}\mathrm{DA} \\
\mathrm{n}=22 \%\end{array}$ & $\begin{array}{l}N A \\
n=7 \%\end{array}$ & $\begin{array}{l}\text { KBBA } \\
n=5 \%\end{array}$ & $\begin{array}{l}\mathrm{GHA} \\
\mathrm{n}=6 \%\end{array}$ & $p$ \\
\hline 1.Obstrüktif uyku apnesi olan & & & & & & & \\
\hline $\begin{array}{l}\text { kadınlarda sadece yorgunluk } \\
\text { olabilir. }\end{array}$ & $46(67,6)$ & $18(64,3)$ & $14(63,6)$ & $7(100)$ & $3(60,0)$ & $4(66,7)$ & 0,400 \\
\hline $\begin{array}{l}\text { 2.Uvulopalatofaringoplasti, } \\
\text { obstrüktif uyku apnesi } \\
\text { olan hastaların çoğu için } \\
\text { iyileştiricidir. }\end{array}$ & $39(57,4)$ & $17(60,7)$ & $16(72,7)$ & $2(28,6)$ & $2(40,0)$ & $2(33,3)$ & 0,156 \\
\hline $\begin{array}{l}\text { 3. Yetişkinler arasında } \\
\text { tahmini obstrüktif uyku } \\
\text { apne prevalansı } \% 2 \text { ile } \% 10 \\
\text { arasındadır. }\end{array}$ & $32(47,1)$ & $12(42,9)$ & $12(54,5)$ & $3(42,9)$ & $3(60,0)$ & $2(33,3)$ & 0,846 \\
\hline $\begin{array}{l}\text { 4. Obstrüktif uyku apneli } \\
\text { hastaların çoğunluğu horlar. }\end{array}$ & $52(76,5)$ & $22(78,6)$ & $16(72,7)$ & $4(57,1)$ & $5(100)$ & $5(83,3)$ & 0,580 \\
\hline $\begin{array}{l}\text { 5. Obstrüktif uyku apnesi } \\
\text { hipertansiyon ile ilişkidir. }\end{array}$ & $58(85,3)$ & $22(78,6)$ & $19(86,4)$ & $6(85,7)$ & $5(100)$ & $6(100)$ & 0,801 \\
\hline $\begin{array}{l}\text { 6. Obstrüktif uyku apne } \\
\text { tanısında gece boyu uyku } \\
\text { çalışması altın standarttır. }\end{array}$ & $66(97,1)$ & $27(96,4)$ & $22(100)$ & $6(85,7)$ & $5(100)$ & $6(100)$ & 0,462 \\
\hline $\begin{array}{l}\text { 7. CPAP tedavisi burun } \\
\text { tıkanıklığına sebep olabilir. }\end{array}$ & $23(33,8)$ & $8(28,6)$ & $7(31,8)$ & $3(42,9)$ & - & $5(83,3)$ & 0,050 \\
\hline $\begin{array}{l}\text { 8. Lazer destekli uvuloplasti, } \\
\text { ağır obstrüktif uyku apnesi için } \\
\text { uygun bir tedavidir. }\end{array}$ & $14(20,6)$ & $4(14,3)$ & $2(9,1)$ & $2(28,6)$ & $3(60,0)$ & $3(50,0)$ & 0,025 \\
\hline $\begin{array}{l}\text { 9. Uyku sırasında üst hava } \\
\text { yolu kas tonus kaybı, tıkayıcı } \\
\text { uyku apnesine sebep olur. } \\
\text { 10. Çocuklarda obstrüktif uyku }\end{array}$ & $55(80,9)$ & $22(78,6)$ & $16(72,7)$ & $7(100)$ & $5(100)$ & $5(83,3)$ & 0,564 \\
\hline $\begin{array}{l}\text { apnesinin en yaygın sebebi } \\
\text { büyük tonsil ve geniz etidir } \\
\text { 11. Obstrüktif uyku apne } \\
\text { șüphesi olan hastaların }\end{array}$ & $61(89,7)$ & $27(96,4)$ & $18(81,8)$ & $6(85,7)$ & $4(80,0)$ & $6(100)$ & 0,255 \\
\hline $\begin{array}{l}\text { değerlendirilmesinde } \\
\text { kraniyofasiyal ve orofaringeal } \\
\text { muayene yararlıdır. }\end{array}$ & $63(92,6)$ & $26(92,9)$ & $21(95,5)$ & $5(71,4)$ & $5(100)$ & $6(100)$ & 0,307 \\
\hline 12. Yatma zamanı alkol & & & & & & & \\
\hline $\begin{array}{l}\text { kullanımı obstrüktif uyku } \\
\text { apnesini artırır } \\
\text { 13. Tedavi edilmeyen obstrüktif }\end{array}$ & $58(85,3)$ & $22(78,6)$ & $20(90,9)$ & $6(85,7)$ & $5(100)$ & $5(83,3)$ & 0,760 \\
\hline $\begin{array}{l}\text { uyku apnesi yüksek trafik } \\
\text { kazası insidansıyla ilişkilidir. } \\
\text { 14. Erkeklerde } 43 \mathrm{~cm} \text { ve üzeri }\end{array}$ & $67(98,5)$ & $27(96,4)$ & $22(100)$ & $7(100)$ & $5(100)$ & $6(100)$ & 1,000 \\
\hline $\begin{array}{l}\text { yaka ölçüsü obstrüktif uyku } \\
\text { apnesi ile ilişkilidir. }\end{array}$ & $40(58,8)$ & $18(64,3)$ & $11(50,0)$ & $4(57,1)$ & $2(40,0)$ & $5(83,3)$ & 0,534 \\
\hline $\begin{array}{l}\text { 15. Obstrüktif uyku apnesi } \\
\text { kadınlarda erkeklerden daha } \\
\text { yaygındır. }\end{array}$ & $51(75,0)$ & $19(67,9)$ & $16(72,7)$ & $7(100)$ & $4(80,0)$ & $5(83,3)$ & 0,560 \\
\hline $\begin{array}{l}\text { 16. CPAP, ağır obstrüktif } \\
\text { uyku apnesi için ilk tedavi } \\
\text { şeçeneğidir. }\end{array}$ & $31(45,6)$ & $15(53,6)$ & $8(36,4)$ & $4(57,1)$ & $1(20,0)$ & $3(50,0)$ & 0,557 \\
\hline 17. Yetişkinlerde bir saatte & & & & & & & \\
\hline $\begin{array}{l}5 \text { 'ten az apne veya hipopne } \\
\text { normaldir. }\end{array}$ & $45(66,2)$ & $19(67,9)$ & $12(54,2)$ & $5(71,4)$ & $4(80,0)$ & $5(83,3)$ & 0,698 \\
\hline $\begin{array}{l}\text { 18. Kardiak aritmiler tedavi } \\
\text { edilmemiş obstrüktif uyku } \\
\text { apnesi ile ilişkili olabilir. }\end{array}$ & $62(91,2)$ & $23(82,1)$ & $21(95,5)$ & $7(100)$ & $5(100)$ & $6(100)$ & 0,455 \\
\hline
\end{tabular}


Tablo 4. Asistan Hekimlerin OSAKA anketindeki tutum ifadelerine ilişkin puanlar

\begin{tabular}{|c|c|c|c|c|c|c|}
\hline & $\begin{array}{l}\text { Aile } \\
\text { hekimliği } \\
(1)\end{array}$ & $\begin{array}{l}\text { Dahiliye } \\
\text { (2) }\end{array}$ & $\begin{array}{l}\text { Nöroloji } \\
\text { (3) }\end{array}$ & KBB (4) & $\begin{array}{l}\text { Gögüs } \\
\text { hastalıkları } \\
(5)\end{array}$ & $p$ \\
\hline $\begin{array}{l}\text { Klinik bir bozukluk olarak } \\
\text { obstrüktif uyku apnesi }\end{array}$ & $4,68 \pm 0,61$ & $4,27 \pm 0,76$ & $4,00 \pm 1,00$ & $4,00 \pm 1,00$ & $4,33 \pm 0,81$ & $\begin{array}{l}\text { Kwh:7,094 } \\
p=0,131\end{array}$ \\
\hline $\begin{array}{l}\text { Olası obstrüktif uyku } \\
\text { apneli hastaların } \\
\text { tanınması }\end{array}$ & $4,50 \pm 0,69$ & $4,27 \pm 0,82$ & $4,14 \pm 0,90$ & $4,00 \pm 1,00$ & $4,17 \pm 0,75$ & $\begin{array}{l}\text { Kwh: } 2,787 \\
p=0,594\end{array}$ \\
\hline $\begin{array}{l}\text { Obstrüktif uyku apne } \\
\text { riski olan hastaları } \\
\text { belirlemede kendime } \\
\text { güveniyorum }\end{array}$ & $3,32 \pm 0,67$ & $3,55 \pm 1,05$ & $3,43 \pm 0,53$ & $4,40 \pm 0,54$ & $3,50 \pm 0,54$ & $\begin{array}{l}\text { Kwh: } 9,811 \\
p=0,044 \\
(1-3)\end{array}$ \\
\hline $\begin{array}{l}\text { Obstrüktif uyku apneli } \\
\text { hastaları yönetmede } \\
\text { yeteneğime güveniyorum }\end{array}$ & $2,71 \pm 0,71$ & $2,95 \pm 0,84$ & $3,00 \pm 0,57$ & $4,20 \pm 0,83$ & $3,17 \pm 0,75$ & $\begin{array}{l}\text { Kwh: } 11,353 \\
p=0,023 \\
(1-3)\end{array}$ \\
\hline $\begin{array}{l}\text { CPAP tedavisi alan } \\
\text { hastaları yönetmede } \\
\text { yeteneğime güveniyorum }\end{array}$ & $2,29 \pm 0,76$ & $3,05 \pm 0,89$ & $2,00 \pm 0,00$ & $3,20 \pm 0,83$ & $2,83 \pm 0,40$ & $\begin{array}{l}\text { Kwh: } 15,926 \\
p=0,003 \\
(2-3 ; 2-1)\end{array}$ \\
\hline
\end{tabular}

Kwh: Kruskal Wallis testi

Tablo 5. OSAKA anketindeki bilgi puanları, tutum puanları ve yaş, asistanlık -meslek yılı ilişki

\begin{tabular}{|c|c|c|c|c|c|c|c|c|}
\hline & & $(\mathrm{A})$ & (B) & (C) & (D) & $(E)$ & $(\mathrm{F})$ & $(G)$ \\
\hline OSAKA bilgi puanı (A) & $\begin{array}{l}\mathrm{r} \\
p\end{array}$ & - & & & & & & \\
\hline OSAKA genel tutum puanı & $\mathrm{r}$ & 0,236 & & & & & & \\
\hline (B) & $p$ & 0,053 & & & & & & \\
\hline OSAKA önem tutum puanı & $r$ & 0,023 & 0,541 & & & & & \\
\hline (C) & $p$ & 0,850 & 0,000 & & & & & \\
\hline OSAKA güven tutum puanı & $r$ & 0,239 & 0,771 & $-0,047$ & & & & \\
\hline (D) & $p$ & 0,050 & 0,000 & 0,706 & & & & \\
\hline \multirow{2}{*}{ Yaş (E) } & $\mathrm{r}$ & 0,021 & 0,112 & 0,031 & 0,026 & & & \\
\hline & $p$ & 0,863 & 0,365 & 0,799 & 0,830 & & & \\
\hline \multirow{2}{*}{ Asistanlık yılı (F) } & $r$ & $-0,015$ & 0,257 & 0,173 & 0,154 & 0,703 & & \\
\hline & $p$ & 0,903 & 0,035 & 0,157 & 0,210 & 0,000 & & \\
\hline \multirow{2}{*}{ Meslek yılı (G) } & $r$ & 0,057 & 0,202 & 0,151 & 0,094 & 0,817 & 0,830 & \\
\hline & $p$ & 0,645 & 0,099 & 0,220 & 0,445 & 0,000 & 0,000 & \\
\hline
\end{tabular}

\section{Tartışma}

OUAS, teşhis ve tedavi edilmediği taktirde olumsuz sonuçlara neden olan global bir sorundur [9]. Dünya çapında gelişmekte olan ülkelerde kadınların \%93'ünde, erkeklerin $\% 82$ 'sinde OUAS hala teşhis edilmemiş durumdadır [10]. Bu aşamada hem hekimlerin bilgi ve yaklaşımı hem de hastaların farkındalığı oldukça önemlidir. OSAKA anketi, hekimlerin OUAS hakkındaki bilgilerini, farkındalıklarını, hastalığı tanıma ve yönetmedeki tutumlarını değerlendirmede oldukça etkili bir ankettir [8].
Asistan hekim eğitimi, uzman tıp doktorluğu öncesinde verilen uzman doktorluk için gereken bilgi, tutum ve yaklaşımı içeren kapsamlı bir eğitim sürecidir. Çalışmada asistan hekimlerin bilgi ve tutum puanları ile yaş ve cinsiyetleri arasında anlamlı bir ilişki bulunmadı. Schotland ve Jeffe [8], hekimlerin bilgi puanı ve güven tutum puanı arasında yaş ile ilişki bulurken, diğer tutum puanları ile aralarında herhangi bir ilişki saptamamışlardır. Yine başka bir çalışmada yaş ile ilişkili olarak büyük yaş, daha düşük bilgi puanları ile ilişkiliyken, tıbbi uygulamada artan yıllar ve daha yüksek düzeyde uzmanlık eğitimi 
daha iyi bilgi ile ilişkilendirilmiştir [9]. Çalışmada herhangi bir farkılılk saptanmamasını, çalışma popülasyonundaki kişilerin yaşlarının birbirlerine çok yakın olması ile ilişkilendirdik.

Uzmanlık alanları ile bilgi puanları arasındaki ilişki incelendiğinde, aralarında istatistiksel herhangi bir farklılık saptanmadı ancak en yüksek puanlar sırasıyla göğüs hastalıkları ve KBB bilim dallarında bulundu. Al Khafaji ve ark.'nın [11] yaptığı bir çalışmada iç hastalıkları hekimlerinin aile hekimlerine göre bilgi puanlarının anlamlı derecede yüksek olduğu bulunmuş. Yine Türkiye'de Gelir ve ark.'nın [7] yaptığı bir çalışmada da göğüs hastalıkları, nörolog ve psikiyatristlerin daha yüksek puanlar aldığı gösterilmiştir. Çalışmamızda uzmanlık alanlarına göre farklılığın olmamasını, hastanedeki bilim dallarına göre asistan hekim dağılımının farklı olması ile ilişkindirdik. Çalışmadaki asistan hekimlerin bilgi puanlarının ortalaması, OSAKA'nın geliştirildiği Schotland ve Jeffe [8] yapmış olduğu çalışma ortalamalarına göre düşük, Orta Doğu ve Kuzey Afrika çalışması [11] ile benzer, Nijerya'daki çalışmanın ortalamasına [9] göre daha yüksek saptandı. Bu durumun tıp fakültelerinde teşhis olanaklarının ve uyku tıbbına ayrılan eğitim saatlerinin arttırılması gibi faktörlerle gelişmeye katkıda bulunabileceği belirtilmiştir [1].

Çalışmadaki asistan hekimlerin en çok doğru cevaplandırdıkları bilgi soruları diğer çalışmalardakine benzer oranda 13. ve 6 . sorulardı [8, 11]. Bu sorular tedavi edilmemiş OUAS'ın trafik kazalarına sebep olabileceğinin bilinmesi ve OUAS tanısı için altın standart polisomnografi olduğunun bilinmesiyle asistan hekimlerin, OUAS tanısının ve eşlik edebilecek komorbiditelerin farkındalıklarının yüksek olduğunu gösterir. Asistan hekimlerin bilgi puanlarının en düşük olduğu sorular 7 . ve 8. sorular olup bunların tedavi yaklaşımı ve yönetimi ile ilişkili sorular olması nedeniyle, tedavi farkındalıklarının yetersiz olduğunu göstermektedir.

Çalışmada önceki çalışmalara benzer şekilde çoğu hekimde OUAS'ın klinik olarak tanımlamasının ve risk altındaki kişileri tanımanın öneminin farkındalıklarının oldukça yüksek olduğu sonucuna ulaştık. Ancak hekimlerin OUAS tedavisini yönetmede kendilerine güven puanlarının oldukça düşük olduğu görülmüştür [11-14]. Fakat KBB asistan hekimlerinde diğer bölümlere göre, OUAS hastalarını yönetmede kendine güven anlamlı şekilde yüksek saptandı. $\mathrm{Bu}$ durumun OUAS hastalarının tanı ve tedavi amacıyla KBB'ye başvurularının ve asistan hekimlerin bu vakalarla karşılaşma sıklığının fazla olması ile ilişkili olabileceğini düşündük. OUAS hastaları tanı öncesi aile hekimliği, nöroloji kliniklerine başvursa dahi tedavi sonrası takiplerinin bu bölümler tarafından yapılmaması nedeniyle çalışmada nöroloji ve aile hekimliği asistan hekimlerinde CPAP tedavisi alan hastaları yönetmede kendine güven puanları düşük saptandı.

Çalışmada bilgi puanları ile ortalama tutum ve güven puanları arasında herhangi bir ilişki saptanmazken, bilgi puanı ve önem tutum puanları arasında Al Khafaji ve ark.'nın [11] çalışmasına benzer şekilde, pozitif yönde anlamlı korelasyon saptandı. Tutum puanlarıla asistanlık yılı, yaş ilişkisi incelendiğinde, yine kişilerin yaş dağılımının birbirine çok yakın olmasıyla ilişkili olarak yaşın tutum puanlarına herhangi bir etkisi görülmemiştir. Ancak asistanlık yılı arttıkça ortalama tutum puanlarının arttığı izlenmiştir. Eğitim sürecinde yıllar içinde gerek alınan eğitimler, gerekse karşılaşılan vaka sayısının artışı, asistan hekimlerin tutumlarını olumlu yönde etkilemektedir.

Asistan hekim sayılarının az ve sayı dağıımının farklı olması bu çalışmanın kısıtlılıkları arasındadır. İlerleyen dönemde Türkiye çapında ve farklı bölümlerin de dahil olduğu bir çalışma planlanması önerilmektedir.

Sonuç olarak, bu çalışma OUAS ile karşılaşabilecek bölümlerdeki asistan hekimlerin hem bilgi düzeylerini ölçen hem de yaklaşımlarını değerlendiren bir çalışmadır. Asistan hekimlerin OUAS bilgi ve tutumlarının birbirinden çok farklı olmadığını ancak bazı eksiklikler olduğu tespit edildi. Hekimlerin OUAS tanı ve tedavi uygulamalarını geliştirmek esas olduğu görüşüne varılmıştır. Bu gelişim, tıp fakültesinden itibaren başlayan ve tıp asistan hekimlik eğitim sürecinde de devam edecek eğitimlerin verilmesi, uyku tıbbı rotasyonları ve OUAS tarama programlarının uygulanması ile sağlanabilir.

Çıkar ilişkisi: Yazarlar çıkar ilişkisi olmadığını beyan eder. 


\section{Kaynaklar}

1. Williams NJ, Nunes JV, Zizi F, et al. Factors associated with referrals for obstructive sleep apnea evaluation among community physicians. J Clin Sleep Med 2015;11:23-26. https://doi.org/10.5664/jcsm.4356

2. Stansbury RC, Strollo PJ. Clinical manifestations of sleep apnea. J Thorac Dis 2015;7:298-310. https://doi. org/10.3978/j.issn.2072-1439.2015.09.13

3. Bradley TD, Floras JS. Obstructive sleep apnoea and its cardiovascular consequences. Lancet 2009;373:8293. https://doi.org/10.1016/S0140-6736(08)61622-0

4. Girotto E, Bortoletto MSS, González AD, et al. Working conditions and sleepiness while driving among truck drivers.Traffic Inj Prev 2019;20:504-509. https://doi.org /10.1080/15389588.2019.1609670

5. Yılmaz S, Calikoglu EO, Kosan Z. for an Uncommon Neurosurgical Emergency in a Developing Country. Niger J Clin Pract 2019;22:1070-1077. https://doi. org/10.4103/njcp.njcp

6. Almohaya A, Qrmli A, Almagal N, et al. Sleep medicine education and knowledge among medical students in selected Saudi Medical Schools. BMC Med Educ 2013;13:133. https://doi.org/10.1186/1472-6920-13133

7. Gelir E, Ardiç S, Izci B. A questionnaire survey among Turkish physicians about sleep disorders. Tuberk Toraks 2004;52:348-355.

8. Schotland HM, Jeffe DB. Development of the obstructive sleep apnea knowledge and attitudes (OSAKA) questionnaire. Sleep Med 2003;4:443-450. https://doi.org/10.1016/s1389-9457(03)00073-x

9. Ozoh OB, Ojo OO, Iwuala SO, Akinkugbe AO, Desalu OO, Okubadejo NU. Is the knowledge and attitude of physicians in Nigeria adequate for the diagnosis and management of obstructive sleep apnea? Sleep Breath 2017;21:521-527. https://doi.org/10.1007/s11325-016$1407-z$

10. Young T, Finn L. Epidemiological insights into the public health burden of sleep disordered breathing: sex differences in survival among sleep clinic patients. Thorax 1998;53:16-19. https://doi.org/10.1136/ thx.53.2008.s16

11. Al Khafaji H, Bilgay IB, Tamim H, Hoteit R, Assaf G. Knowledge and attitude of primary care physicians towards obstructive sleep apnea in the Middle East and North Africa region. Sleep Breath 2020. https://doi. org/10.1007/s11325-020-02137-7

12. Chang JWR, Akemokwe FM, Marangu DM, et al. Obstructive sleep apnea awareness among primary care physicians in Africa. Ann Am Thorac Soc 2020;17:98-106. https://doi.org/10.1513/ AnnalsATS.201903-2180C
13. Marran NM, Bahri AA, Kariri KI, et al. Recent medical graduates' knowledge and attitude toward obstructive sleep apnea in the Southern Region of Saudi Arabia: a cross-sectional study. Egypt J Intern Med 2019;31:8691. https://doi.org/10.4103/ejim.ejim_70_18

14. Cherrez Ojeda I, Jeffe DB, Guerrero T, et al. Attitudes and knowledge about obstructive sleep apnea among Latin American primary care physicians. Sleep Med 2013;14:973-977. https://doi.org/10.1016/j. sleep.2013.06.005

Teşekkürler: Pandemi döneminde yoğun özveriyle çalışan ve çalışmada katkılarını esirgemeyen tüm asistan hekimlere teşekkür ediyoruz.

Etik kurul onayı: Çalışma, Pamukkale Üniversitesi Girişimsel Olmayan Klinik Araştırmalar Etik Kurulu'nun 02.02.2021 tarih ve 03 sayısı ile onay alınmıştır.

\section{Yazarların makaleye olan katkıları}

S.T.veN.E. çalışmanın ana fikrinive hipotezini kurgulamışlardır. N.E. teoriyi geliştirmiş, gereç ve yöntem bölümünü düzenlemişlerdir. Sonuçlar kısmınındaki verilerin değerlendirmesini S.T. ve N.E. yapmışlardır. Makalenin tartışma bölümü S.T. tarafından yazıımış, N.E. gözden geçirip gerekli düzeltmeleri yapmış ve onaylamıştır. Ayrıca tüm yazarlar çalışmanın tamamını tartışmış ve son halini onaylamıştır. 